\title{
COMPACTNESS OF OPERATOR INTEGRATORS
}

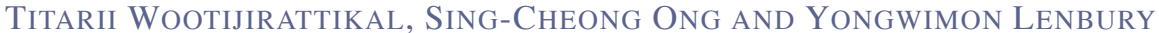

\begin{abstract}
A function $f$ from a closed interval $[a, b]$ to a Banach space $X$ is a regulated function if one-sided limits of $f$ exist at every point. A function $\alpha$ from $[a, b]$ to the space $\mathfrak{B}(X, Y)$, of bounded linear transformations form $X$ to a Banach space $Y$, is said to be an integrator if for each $X$-valued regulated function $f$, the Riemann-Stieltjes sums (with sampling points in the interior of subintervals) of $f$ with respect to $\alpha$ converge in $Y$. We use elementary methods to establish criteria for an integrator $\alpha$ to induce a compact linear transformation from the space, $\operatorname{Reg}(X)$, of $X$-valued regulated functions to $Y$. We give direct and elementary proofs for each result to be used, including, among other things, the fact that each integrator $\alpha$ induces a bounded linear transformation, $\widehat{\alpha}$, from $\operatorname{Reg}(X)$ to $Y$, and other folklore or known results which required reading large amount of literature.
\end{abstract}

Mathematics subject classification (2010): Primary 46G10, Secondary 28B05.

Keywords and phrases: Banach space, operator, regulated function, integrator, semivariation.

\section{REFERENCES}

[1] K. K. AYER AND P. Y. LEE, The dual of the space of functions of bounded variation, Math. Bohem. 131 (2006), 1-9.

[2] M. BRokate AND P. KREJČÍ, Duality in the space of regulated functions and the play operator, Math. Z. 245 (2003), 667-668.

[3] J. Dieudonné, Foundations of Modern Analysis, Acedemic Press, 1969.

[4] L. FERnANDES AND R. ARBACH, Integral functionals on $C^{*}$-algebra of vector-valued regulated functions, Ann. Funct. Anal. 3 (2012), no. 2, 21-31.

[5] D. Franková, Regulated functions, Math. Bohem. 116 (1991), 20-59.

[6] C. S. HöNIG, Volterra Stieltjes-Integral Equations - Functional Analytic Methods; Linear Constraints, Notas de Mathemática, no. 56, North-Holland, 1975.

[7] $\breve{S}$. SCHWABIK, A survey of some new results for regulated functions, vol. 28 , Seminario Brasileiro de analise, 1988.

[8] Š. SCHWABIK, Linear operator in the space of regulated functions, Math. Bohem. 117 (1992), no. 1, 79-92.

[9] M. TVRDÝ, Linear bounded functionals on the space of regular regulated functions, Tatra Mt. Math. Publ. 8 (1996), 203-210.

[10] M. TVRDÝ, Differential and integral equations in the space of regulated functions, Mem. Differential Equations Math. Phys. 25 (2002), 1-104. 